\title{
Determinants of Cereal Crops Productivity: In Case of Kecha Birra Woreda, Snnpr, Ethiopia
}

\author{
Mr. Takele Ayele Mr. Tesfaye Melaku \\ Department of Economics Jimma University, Ethiopia
}

\begin{abstract}
This study conducted to investigate the determinants of cereal crop productivity of small household farmers in southern region, a case of Kecha Birra woreda.To study the determinants of cereal crop productivity descriptive and econometrics analysis was carried out, a positive increasing trend was found in agricultural productivity and data collection was from rural household farmers selected through random sampling techniques for the collected cross-sectional data on 100 samples of the farmers at household level. Agriculture plays prominent role in the process of economic development for a country. Without achieving substantial increase in agricultural production, no country has moved to take off stage of economic development. The general objective of the study is to assess the determinants of cereal crop productivity in Kecha Birra Woreda. The study found that improved seed, farm size, fertilizer, education, family size, age, and irrigation have the positive effects in the productivity of cereal crops. The sex and credit have negative impact on cereal crops productivity in the study area. Since the improved seed, farm size, fertilizer, family size, credit and irrigation significantly affect the yield capacity of the cereal crops, the farmers should be encouraged in order to use them and the government should provide the access to the farmers.
\end{abstract}

Keywords: Agriculture, Cereal crops, Smallholder farmers

DOI: $10.7176 / \mathrm{JESD} / 10-17-04$

Publication date:September $30^{\text {th }} 2019$

\section{INTRODUCTION}

\subsection{Background of the Study}

Most of the world's 2.1 billion people who live on less than 2 dollars a day live in rural areas and depends on agriculture. The number of rural poor has increased in Africa and south Asia and reduced in East Asia and the pacific(WDR,2008).According to Barrios et al, (2008) agriculture is the main engine for economic growth for sub Saharan African countries . However, feeding the increasing population of sub Saharan African has becomes a critical challenge for most of countries in this area (Owusue et al, 2010). In line with this Diao and Hazel (2010), underscore the existences of two school of thought or debates in African agriculture. These debates focus on potential role of agriculture and industry in improving African development and ability of the agricultural sector to ensure pro-poor growth. Hence the argument that agriculture is a large sector and upgrading it leads to a better aggregate growth (Sadoul et al, 2010).

Ethiopia is one of the sub Saharan African countries which liberalize its economy to maintain a sustained economic growth and hence, reduce poverty. Over the last ten years the sustainable economic growth brought with its positive trends in reducing poverty. However, poverty head count is still more prevalent in rural areas (30.4\%) than urban areas (25.7\%) in Ethiopia (CSA, 2010/11). In Ethiopia about 83.9\% 0f total population is live in rural areas and agriculture is their main source of livelihood. Since 2010, agriculture become the second most dominant next service sector of the country economy by providing employment for $80 \%$ of the total labor force and contributes $42.7 \%$ to growth of domestic product and $70 \%$ of foreign exchange earnings (CSA, 2013). Due to its importance, the government of Ethiopia gives high priorities to the agriculture sector by setting strategy of agricultural development led industrialization (ADLI). The main goal of agricultural policy is not only achieving sustainable increase in agricultural production and productivity of smallholder farmers, but also accelerates agricultural commercialization and agro-industrial development in the country (PIFW 2010-2020).

According to Kecha Birra woreda agricultural and rural development bureau report (2016), the woreda has suitable climatic condition for production of most dominant cereal crops such as Wheat, Teff, Barley, and maize which are practiced by small scale farmers in this area. Even though the Woreda has suitable climatic condition for production of these major cereal crops, the wanted amount is not produced, so the focus of this study is to know the determinants of those dominant cereal crops in the study area.

In Africa, particularly in Ethiopia cereal crop production is dominated by smallholder farmers. The yield of cereal is very low because of low adoption of improved agricultural technologies, weather fluctuation, climatic change, rapid population growth, difference in land size holding and livestock. Due to this reason cereal crop productivity in developing countries has not been able to satisfy the food requirement of the people (Hailu, 2008). In addition to above reasons the productivity of cereal crop in Ethiopia was severely restricted due to many recurrent disasters. These are; flood, lack of diversity of items and due to weak subsistence agriculture economy. According to the most recent report of Ethiopian economic association, gaining in the yield level in the farming areas over the past few years for most cereal crops has not been able to increase average yield for most countries 
as a whole (EEA, 2015) .Even though, agriculture is the crucial sector in the national economy, its production and productivity is unsatisfactory. So, an important way to increase cereal crop productivity and agricultural productivity is that reducing constraints of agriculture (natural constraints, economic constraints, social and institutional constraints). These constraints reduced through diffusion of improved seed, land management practice and training farmers (CSA, 2015).

In the country level there were a lot of researchers tried to identify the determinants of cereal crop productivity of small holder farmer, like Endale (2011), Olayem (2015), and Van Dusen(2008), they have tried to study on the variables such as improved seed, farm size ,education level ,age and sex ,but they did not focused in detail about the effects of credit access on cereal crops productivity. So, this study will be different from other studies by giving attention to credit access and the study area which taking the specific area of Kecha Bira woreda and would be expected to ask the following research questions:

*What is the effect of fertilizer adoption on cereal crop productivity in the study area?

*How the land size affect (determine) the cereal crop productivity in the study area?

*What is the impact of credit access on cereal crop productivity?

*What is effect of irrigation on cereal crops productivity?

\section{REVIEWOF LITERATURE}

Agriculture is the science of art of cultivation of soil and rearing of livestock. Agriculture as the primary economic activity is the major economic activity of the world's population .More than $60 \%$ of people of the world depend on agriculture for its livelihood. This means agriculture is the main economic and social development background for almost all countries the world. Agricultural products is used for daily food consumption, source of raw materials for industrial input, contribute to countries economic growth, source of income for individual farmers. Being a major determinants of life of the people in the world due attention should be given to agricultural sector especially to improve the lives of majority engaged its activity (Gosaye, 2008).The term agriculture has different meaning by different individuals, some side it is farming and animals husbanding some may them thing of agribusiness firms. Some agricultural economists have referred to food and fiber industry when describing the agricultural science. They also devised rules for decision in an ever changing uncertain economic and agricultural environment. This rule can be used to make production, consumption, marketing and financial decision. By studying the logic of these managerial rules, we can learn how to adjust managerial decision to the changing environment in which economic and agricultural activity occurs (Dawit et al., 2012).

\section{General overview of cereal crop production}

The small holder farmers use subsistence farming system and most of outputs produced are for family consumption (although, some may be sold or trade in local markets and few staple food crops usually including Wheat, Barley, Sorghum, Teff) are chief source of food intake. Output and productivity are low and only the simplest traditional methods and tools are used. Capital investment is minimal, and land and labor are the principal factors of production. (Addissie, 2008).

Subsistence agriculture is highly risk and uncertain in the region where forms are extensively small and cultivation is dependent on uncertainties of variables such as rain fall. Average output will be low and the peasants will be exposed to very real danger of starvation. According when risky and certainty are high, small holder farmers may be very reluctant to shift from traditional technology and crop pattern to a new one that provides higher yields, but entail greater risk of crop failure (Muuz, 2006).

A cereal crop is generally defined as a grass grown for its small edible seed. It has been the most important source of the world is seed. Cereals as grouped are the most widely adapted crop species. They can be grown under adverse condition with a least some yield. These broad ranges of adaption the efficiency of production the ease with which cereal can be stored make them dependable source of food.

\section{Small holder farmers}

Small holder farmers are farmers which derives their livelihood main from agriculture utilize family labor in farm production most output is produced for family consumption and they are characterized by practical engagement in input and output market which are perfect market. Subsistence farming on small plot of land it is way of life for the vast majority of Ethiopia people and its productivity is low. Inspire of the existence of some unused land and potentially cultivable land only small areas can plant and weeded by farm family at the time when it uses only traditional tools. In some areas traditional farming practices must rely piney on the application of human labor of small pare parcel land. The given limited area of that a farm family can cultivate in the context of a traditional technology and the use of primitive tools. This small area tends to be intensively cultivated as the result they are subject to rapidly diminishing return to increase labor input. In such condition shifting cultivating is the most economic method of using limited suppliers of labor on extensive tracts of land (Tadero, 2008).

Determinants of cereal crop productivity

In developed country, productivity agriculture has significantly increased while per portion of the population in the sector declines. On other hand the economies of low income consequently, it is better to outline factors 
effecting agricultural output specially, cereal crop output by using some method of arrangement. Different authors used deferent classification schemes of agricultural output growth determinants. Wiebe et al., (2011) divides agricultural output growth determinants in to conventional (land, labor physical capital and fertilizer) and nonconventional factors of production which include private and public agriculture research education infrastructure government program and policies and environmental degradation (Senai, 2006).

Millikan and hap well divided the determinant of agricultural output into many categories. These are physical input factors economic, factors, organizational factors, cultural and motivation factors and knowledge factors.

\section{RESEARCH METHODOLOGIES}

The researcher used both primary and secondary data. The Primary data was collected through questionnaire and interview to identify the determinants of cereal crops productivity at kebele level. The secondary data was collected from the relevant report of the woreda bureau of agriculture and rural development and other related theoretical articles.

The researcher applied probability sampling methods of both simple random sampling and proportional formula. To give equal chance the researcher selected five kebeles by using simple random sampling technique, namely Awaye, Gamasha, Ashira, Buge, and lada. Then, by using proportional formula, the researcher selected the respondents from five kebeles households. The way of collecting the data from each kebele was by using random technique, because the houses are not built within municipal plan. The sample size was founded by using Yamane taro sample size formula (1987). Kecha Bira woreda comprise of 22 kebeles having a total of 113,687 populations (KBWAO, 2017).

The formula of Yamane taro: $n=N / 1+N\left(e^{2}\right)$ Where: $n=$ sample size, $\mathrm{N}=$ total population of the five kebeles at household level, $\mathrm{e}=$ error term, $\mathrm{e}=10 \%$

The researcher used $\mathrm{e}=10 \%$, to reduce sample size because of time and budget constraints.

$$
\begin{aligned}
\mathrm{N} & =20588 \\
\mathrm{n} & =20588 / 1+20588(0.1)^{2}=20588 / 1+20588(0.01) \\
\mathrm{n} & =20588 / 2006.88=99.9=100
\end{aligned}
$$

The proportional formula which helps to select unbiased and desirable number of observation from each of the 5 kebeles is like this: $\mathrm{Ni}=(\mathrm{n} / \mathrm{N}) * \mathrm{NS}$, where: $\mathrm{Ni}=$ total number of observation in one kebele, $\mathrm{n}=$ the total number of households in one kebele, $\mathrm{N}=$ the total number of households in five kebeles, NS=the total number of sample size

Therefore, using the above technical formula the proportional number of respondents from each kebele as follows: From Awaye $=(4780 / 20588)(100)=23$

From Gamasha $=(4432 / 20588)(100)=21$

From Ashira $=(3540 / 20588)(100)=17$

From Buge $=(4865 / 20588)(100)=24$

From Lada $=(2971 / 20588)(100)=15$

Method of data analysis

The researcher used both descriptive method and econometrics model to analyze the collected data. Therefore, for this matter, ordinary least square (OLS) estimation technique was applied in the study area to differentiate the determinants of the cereal crop productivity. The reason for using this method is because of the computation procedures of OLS is fairly simple as compared with other econometric methods.

\section{Model specification}

In this study the researcher tried to measure the dependent variable, productivity of cereal crops by measuring the total output per hectare of all produced cereal crops in the study area.

In this study the researcher has been tried to measure productivity of cereal crops by using independent variables such as: improved seed, farm size, fertilizer, education, family size, age, sex, credit and irrigation. The cereal crops productivity model includes these explanatory variables in the form of multiple linear regression function:

$\mathrm{CCP}=\mathrm{F}(\mathrm{IMSD}, \mathrm{FAMS}, \mathrm{FE}, \mathrm{EDU}, \mathrm{FS}, \mathrm{AGE}, \mathrm{SEX}, \mathrm{CR}, \mathrm{I})$

Lnccp $=\beta 0+\beta 1$ ims $d+\beta 2 f a m s+\beta 3 f e+\beta 4 e d u+\beta 5 f s+\beta 6 a g e+\beta 7 s e x+\beta 8 c r+\beta 9 i r+U i$

Where: $\mathrm{CCP}=$ cereal crop productivity, $\mathrm{IMSD}=$ improved seed, $\mathrm{FAMS}=$ farm size, $\mathrm{FE}=$ fertilizer

$\mathrm{EDU}=$ education, $\mathrm{FS}=$ family size, $\mathrm{CR}=$ credit, $\mathrm{I}=$ irrigation, $\beta 0=$ constant term, $\beta \mathrm{i}=$ coefficient of explanatory variables, $\mathrm{Ui}=$ error term (residual term), $\mathrm{Ln}=$ logarithmic indicator

\section{DATA ANALYSIS AND DISCUSSION}

This chapter deals with presentation and analysis of the data gathered from respondents. Secondary data sources are from office of Kecha Bira woreda agriculture and rural development and written sources. Generally, this analysis shows the determinants of cereal crop productivity in SNNPR state in the case of Kecha Bira woreda. 
Table 4.1 distribution of respondents based on sex structure

\begin{tabular}{lcc}
\hline Sex & Number of respondents & Percentage \\
\hline Male & 79 & $79 \%$ \\
Female & 21 & $21 \%$ \\
Total & 100 & $100 \%$ \\
\hline
\end{tabular}

Source: own survey, 2018

As it can be shown in the above table, from the total sample size about $79 \%$ of the respondents are Male headed household; on the other hand the shares of female household heads are $21 \%$. It indicates that the responsibility of male to participate in agricultural activities is more in number compared to females. This shows that imbalance was not unique in social activity and female participation of agriculture was less than male in the study area.

Table 4.2 distribution of respondents according to material status

\begin{tabular}{lcc}
\hline Marital status & Number of respondents & Percentage \\
\hline Married & 50 & $50 \%$ \\
Unmarried & 24 & $24 \%$ \\
Widowed & 16 & $16 \%$ \\
Divorced & 6 & $6 \%$ \\
Total & 100 & $100 \%$ \\
\hline
\end{tabular}

Source: own survey, 2018

According to the above table, the marital status analysis of dimension of respondents, the majority of respondents, about 50\%, are married followed by unmarried $24 \%$, widowed $16 \%$ and divorced where $6 \%$. Generally, the most of respondents are married.

Table 4.3 Age distribution of the respondents.

\begin{tabular}{lcc}
\hline Age & Number of respondents & Percentage \\
\hline $20-30$ & 3 & $3 \%$ \\
$30-40$ & 43 & $43 \%$ \\
$40-50$ & 38 & $38 \%$ \\
Above 50 & 16 & $16 \%$ \\
Total & 100 & $100 \%$ \\
\hline
\end{tabular}

Source: own survey 2018

The above table indicates that the majority of the respondents $43 \%$ are in the age group between $30-40$, only $3 \%$ are in age group $20-30,38 \%$ are in age group between $40-50$ and $16 \%$ are in age group above 50 Years of age. Based on this table, the age structure of respondent implies that most of the respondents are in the productive age groups.

Table 4.4 family size distribution of respondents

\begin{tabular}{ccc}
\hline Family size & Number of respondents & Percentage \\
\hline $1-4$ & 38 & $38 \%$ \\
$5-8$ & 49 & $49 \%$ \\
Above 8 & 13 & $13 \%$ \\
Total & 100 & $100 \%$ \\
\hline
\end{tabular}

Source: own survey, 2018

As we have seen that from the above table, $49 \%$ of respondents $(5-8)$ five up to eight their family number without children and elders in agricultural activities and also $38 \%$ and $14 \%$ of respondents implemented their agricultural work with 1-4 (one up to four) and above the eight family members respectively. The table shows that the respondents they have large family size but less percentage in agricultural activities. Because some of their family members were children and some of them were students. However it is known that labor is the most important factor of production in order to increase scale of production and rising productivity.

Table 4.5 distribution of fertilizer and improved seed of farmer

\begin{tabular}{|c|c|c|c|c|c|c|}
\hline \multicolumn{4}{|c|}{ Distribution of fertilizer } & \multicolumn{3}{|c|}{ Distribution of improved seed } \\
\hline \multirow[t]{5}{*}{ Use } & $\mathrm{Kg} /$ hector & Frequency & Percentage & \multirow{4}{*}{ Use } & \multirow[t]{4}{*}{ Frequency } & \multirow[t]{4}{*}{ Percentage } \\
\hline & $50-100 \mathrm{~kg}$ & 37 & $37 \%$ & & & \\
\hline & $100 \mathrm{~kg}-200 \mathrm{~kg}$ & 34 & $34 \%$ & & & \\
\hline & $>200 \mathrm{~kg}$ & 22 & $22 \%$ & & & \\
\hline & Total & 93 & $93 \%$ & & 90 & $90 \%$ \\
\hline Not & & 7 & $7 \%$ & Not use & 10 & $10 \%$ \\
\hline Tota & & 100 & $100 \%$ & & 100 & $100 \%$ \\
\hline
\end{tabular}

Source own survey, 2018 
As survey indicated the farmers of study area used both of them as well. This was from the 100 total respondents $93(93 \%)$ of household used the fertilizer while the other $7(7 \%)$ does not used the fertilizer. From $93 \%$ of respondent that used fertilizer $37(37 \%)$ of the used less than $100 \mathrm{~kg}$ per hector, $34(34 \%)$ of them used $100 \mathrm{~kg}-$ $200 \mathrm{~kg}$ per hectare and $22(22 \%)$ of them where used above $200 \mathrm{~kg}$ per hectare of fertilizer during 2008/09 cropping season. Therefore, the farmers in the study area adopted fertilizer.

The other survey data indicate that the using seed which was from total respondent $90(90 \%)$ of respondents are the using improved seeds and the other $10(10 \%)$ of them are not using improved seed. Generally, the above table shows that, in the study area famers used both fertilizer and improved seed and the number of fertilizer and improved users were very high relative to not users in the study area. Therefore the use of fertilizer and improved seed increases the output of the cereal crop productivity compared to not use.

Table 4.6 distribution of credit access

\begin{tabular}{ccc}
\hline & Frequency & Percentage \\
\hline Yes & 74 & $74 \%$ \\
No & 26 & $26 \%$ \\
Total & 100 & $100 \%$ \\
\hline
\end{tabular}

Source: own survey, 2018

The result of this survey data indicates that from the total respondents about $26(26 \%)$ of respondent does not get enough credit access from organizations, while the other respondents $74(74 \%)$ of them get credit access from different organizations. Based on this result the farmers who get enough credit access from different organizations are expected to have confidence to purchase agricultural input from the government and private organizations during 2008/09cropping season.

Table 4.7 Distribution of farm size in hectares of households

\begin{tabular}{ccl}
\hline Determinant & Frequency & Percentage \\
\hline 0 hect & 0 & $0 \%$ \\
$0.5 .-2$ hect & 19 & $19 \%$ \\
$2-4$ hect & 63 & $63 \%$ \\
Above 4 & 18 & $18 \%$ \\
Total & 100 & $100 \%$ \\
\hline
\end{tabular}

Source; own survey, 2018

From the above table the holding size in hectare in the study area19 $(19 \%)$ of respondents had between $(0.5$ 2) hectare of land size, $63(63 \%)$ of respondents had 2- 4hectares of land size. This implied that all respondents had their own land which means about $100 \%$ respondents have their own land.

Table 4.8 determinants of crop productivity

\begin{tabular}{lcc}
\hline Major determinant/constraints & No respondents & Average \\
\hline Shortage of rain fall & 88 & 0.88 \\
Shortage of inputs /factors & 54 & 0.54 \\
Back ward technology & 27 & 0.27 \\
Poor infrastructure & 48 & 0.48 \\
In adequate market & 32 & 0.32 \\
\hline
\end{tabular}

Source: own survey, 2018

Table 4.8 indicates that averagely (0.88) 88 of the respondents affected by droughts/shortage of rain fall which results in highly determined crop productivity. The other constraints from the averagely (0.54)54 of the respondents were affected by shortage of input. It is improved by providing required inputs or sufficient input to farmers to increase crop productivity.

The above table 4.8 show averagely (0.27)27 of the respondents were used backward technology is another constraint for productivity affected by this problem. Poor infrastructure and inadequate market are also another determinant of crop productivity averagely (0.48)48 and (0.32)32 of respondents respectively were determined by these problems.

\subsection{The Result of Econometrics Analysis: Econometric result}

This section is devoted to the discussion of regression results with the aim of addressing the determinants of cereal crops productivity in terms of some qualitative and quantitative variables. In particular, the purpose of the model is to determine the factors that explain the cereal crops productivity.

The adequacies of the model have to be supported by diagnostic tests before proceeding to interpret the econometrics result and then the data fits for next analysis since it passes all diagnostic tests. 


\subsubsection{The Regression result}

Table 4.11 OLS regression result

. reg inccp imsd fams fe edu fs age sex cr $i$

\begin{tabular}{r|crc} 
Source & SS & df & MS \\
\hline $\begin{array}{r}\text { Model } \\
\text { Residual }\end{array}$ & 481655.966 & 9 & 53517.3295 \\
\hline Total & 518884.51 & 99 & 5241.25768
\end{tabular}

$\begin{array}{llr}\text { Number of obs } & = & 100 \\ \text { F( 9, 90) } & 129.38 \\ \text { Prob }>\text { F } & =0.0000 \\ \text { R-squared } & =0.9283 \\ \text { AdjR-squared } & =0.9211 \\ \text { Root MSE } & =20.338\end{array}$

\begin{tabular}{r|rlrrrr}
\hline Inccp & Coef. & std. Err. & $t$ & P $>|t|$ & [95\% Conf. Interval] \\
\hline imsd & 27.43752 & 9.861908 & 2.78 & 0.007 & 7.845123 & 47.02993 \\
fams & 6.090085 & 1.432265 & 4.25 & 0.000 & 3.244641 & 8.93553 \\
fe & .7123014 & .0358031 & 19.89 & 0.000 & .6411723 & .7834306 \\
edu & .7341015 & .9159892 & 0.80 & 0.425 & -1.085671 & 2.553874 \\
fs & 1.99667 & .9292174 & 2.15 & 0.034 & .1506171 & 3.842722 \\
age & .1237559 & .4688317 & 0.26 & 0.792 & -.8076601 & 1.055172 \\
sex & -1.586567 & 6.365685 & -0.25 & 0.804 & -14.23311 & 11.05998 \\
cr & -22.90968 & 6.504452 & -3.52 & 0.001 & -35.83191 & -9.987449 \\
i & 16.79021 & 7.521063 & 2.23 & 0.028 & 1.848302 & 31.73211 \\
cons & -21.042 & 19.56792 & -1.08 & 0.285 & -59.91709 & 17.83309 \\
\hline
\end{tabular}

Source; own survey, 2018

By using this formula, the result of regression can be put the format of cereal crops productivity function as follows: Inccp $=-21.042+27.43 \mathrm{imsd}+6.09 \mathrm{fams}+0.712 \mathrm{fe}+0.734 \mathrm{edu}+1.99 \mathrm{fs}+0.123 \mathrm{age}-1.586 \mathrm{sex}-22.9 \mathrm{cr}+16.79 \mathrm{irr}$
$\mathrm{Se}=$
(19.56)
(9.86)
(1.43)
(0.035)
(0.915)
(0.92)
(0.468) (6.36)
(6.5)
(7.52)

Where; results in the brackets are standard errors

$\mathrm{P}$-value of the model indicates the reliability of independent variable to predict cereal crops productivity in Kecha Bira woreda. The independent variable with p-value less than 0.05 showsthat they are statistically significant. Explanatory variables like improved seed, farm size, fertilizer, family size, credit, irrigation have significant impact on the model with p-value of $0.007,0.000,0.000,0.034,0.001$ and 0.028 respectively.

The overall significance of the variables is tested by Prob $>$ F. If the value of Prob $>$ F is less than $0.05(5 \%$ level of significance) then, the variables included in the model are jointly statistically significant. As the result of regression shows Prob $>F=0.0000$ so, the variables included in the model are jointly statistically significant.

Improved seed: The regression result shows that improved seed positively affects agricultural output. The semi elasticity of output with respect to improved seed is 27.43. This show that other things remain constant; the output produced by the users of improved seed is greater than that of non-users by 27.43 quintal. It is also significant at $1 \%$ the level of significance.

Farm size: The regression result shows that farm size positively affects agricultural output. The semi elasticity of output with respect to farm size is 6.09 . This show that other things remain constant, a 1 unit /hectare change in land size leads to on average about 6.09 unit/quintal increases in the output of farmers. This means that, the size of land increase or decrease leads to agricultural output to increase or decrease, other things being unchanged. It is statistically significant at $1 \%$ level of significance.

Fertilizer: As the regression result shows that fertilizer positively affects cereal crop production in the study area. The semi elasticity of cereal crop productivity with respect to fertilizer is 0.712 . The implication is that other things remains constant, as the farmer increases the using fertilizer by $1 \mathrm{~kg}$, cereal crop production increases by 0.712 quintal. It is also significant at $1 \%$ level of significance.

Family size: The regression result shows that family size affects cereal crop production positively and it is statistically significant at $5 \%$ level of significance. The responsiveness of cereal crop production with respect to family size is 1.99 . meaning other things remain constant, as the family size increases by one person, quantity of cereal crops increases by 1.99 unit/quintal. The implication is that as the family size increases working power increases and thus production.

Credit service: It is significant at $1 \%$ level of significance and its coefficient is negative.. The negative coefficient indicates that in the study area the microfinance institutions which give credit services to farmers are inadequate.

Irrigation: The regression result shows that irrigation affects cereal crop production positively. The semi elasticity of output with respect to irrigation is 16.79 in the study area. This shows that other things remain constant; the output produced by the users of irrigation is greater than that of non-users by 16.79 quintal. It is also significant at $5 \%$ level of significance.

The estimated coefficients of education level, age of households, and sex are statistically insignificant. The researcher understood that the reason behind to these insignificant variables may be due to the sample size of the study. Then, the researcher recommends this in the recommendation part of the study. But based on their signs of coefficients, they are economically significant even if there is no need of interpretation for these variables.

As the above regression result table shows that R-squared $=0.928$, which implies $92 \%$ of output function is 
explained by the selected explanatory variables. In other words $92 \%$ of variation of the dependent variable is due to the variation of the independent variable which are included in the model and the remaining variation $0.8(8 \%)$ is explained by the variable which are not included in the model. If the value of adjusted R-squared is higher, the greatest the goodness of fit of the regression plans to be the sample observation. Therefore, the adjusted R-squared (0.921)obtained in the regression model reveals that there is good fitness of values for a given result.

\section{CONCLUSION}

Agriculture is back bone of our country's economy and its growth. Therefore it is the center of policy making. As result government of Ethiopia takes attention to agricultural sector. This study analyzed a onetime visit crosssectional data on 100 representative samples of farmers at household level to empirically access the determinants of cereal crops productivity in Kecha Birraworeda. For this purpose the ordinary least square method used. The primary and secondary data were collected from the randomly selected kebeles and KBWARDO respectively. In this study the descriptive analysis and the econometric model were applied. The descriptive result shows socio economic, institutional and demographic characteristics of respondents by using percentage.

For econometric analysis the ordinary least square model was employed so as to identify the determinants of cereal crop productivity in five randomly selected kebeles in Kecha Birra woreda. The dependent variable that was the being cereal crops productivity was regressed against the nine explanatory variables. The study found that the independent variables like improved seed, farm size, fertilizer, education level, family size, age of households, and irrigation were positively affected the productivity of the cereal crops in the study area. Whereas the variables like sex and credit service negatively affected the productivity of cereal crops. From the explanatory variables improved seed, farm size, fertilizer, family size, credit service, and irrigation significantly affected the productivity at $10 \%, 5 \%$ and $1 \%$ level of significance. The remaining variables education level, age of households, and sex were insignificantly affecting the cereal crops productivity in the study area.

Finally the sample respondent was asked to mention the major problem that faced by farmers agricultural input supply and the researcher concluded that the availability of inputs such as improved seed, fertilizer, farm size, credit and age are important for expanding the cereal crops productivity in the study area.

\section{REFERENCES}

Anbesa, K. (2000). Improving food security in Africa, ECA/FAO agricultural division, monograph No 14. Addis Ababa, Ethiopia.

Central statistics Agency. (2011).

Dejene Abesha. (2000). Agricultural economics societies of Ethiopia (AESE). 6th annual conference chamber . Addis Ababa.

Dejene, A. (2011). Agricultural development; theory, policy and practice. Addis Ababa, Ethiopia.

Ethiopian Economic Association (EEA). (2005). Land registration and certification in Ethiopia.

Ethiopian Economic Association (EEC). (2006). Evaluation of Ethiopian Agricultural extensions with a particular emphasis on the particparatory demonstration and Training extension system(PADETES). Addis Ababa, Ethiopia.

Ethiopian Economic Association(EEA). (2004). Industrialization and Industrial policy of Ethiopia, report on Ethiopian Economy. Addis Ababa.

Ethiopian Economic Association(EEA). (2010). procedings of the seventh international conference on the Ethiopian Economy.Volume 2. Addis Ababa, Ethiopia.

Food and Agricultural organization (FAO). (2010,2014).

Minstry of Agriculture. (2005).

Minstry of Agriculture. (2010). Agricultural policies and strategies.

Minstry of Agriculture and Roral development policies. (2012). Report of the strategic workshop of holders on the review of policy and laws.

MOFED. (2002). Sustainable development and poverty reduction program. Addis Ababa, Ethiopia.

United Nation (UN). (2014). report.

Van Dusen. (2008). Conservation of crop genetic resources in the Mexican Milpa system. 


\section{APPENDIX 2}

. vif

\begin{tabular}{r|rr} 
Variable & VIF & $1 / V I F$ \\
\hline imsd & 2.66 & 0.376053 \\
i & 1.93 & 0.518260 \\
fams & 1.89 & 0.527990 \\
cr & 1.89 & 0.529307 \\
age & 1.44 & 0.692923 \\
sex & 1.20 & 0.83566 \\
edu & 1.18 & 0.847846 \\
fs & 1.16 & 0.859930 \\
\hline Mean VIF & 1.10 & 0.910589 \\
\hline
\end{tabular}

\section{Heteroscedasticity test result}

hettest

Breusch-pagan / cook-wejsberg test for heteroskedasticity

Ho: constant variance

variables: fitted values of 1 nccp

$\begin{array}{ll}\text { chiz(1) } & 0.95 \\ \text { Prob chiz } & =0.3291\end{array}$

Model misspecification test result

- ovtest

Ramsey RESET test using powers of the fitted values of $1 \mathrm{nccp}$ HO: model has no omitted variables

$$
\begin{array}{ll}
\text { F }(3,87)= & 2.55 \\
\text { Prob }>F= & 0.0608
\end{array}
$$

Normality test result

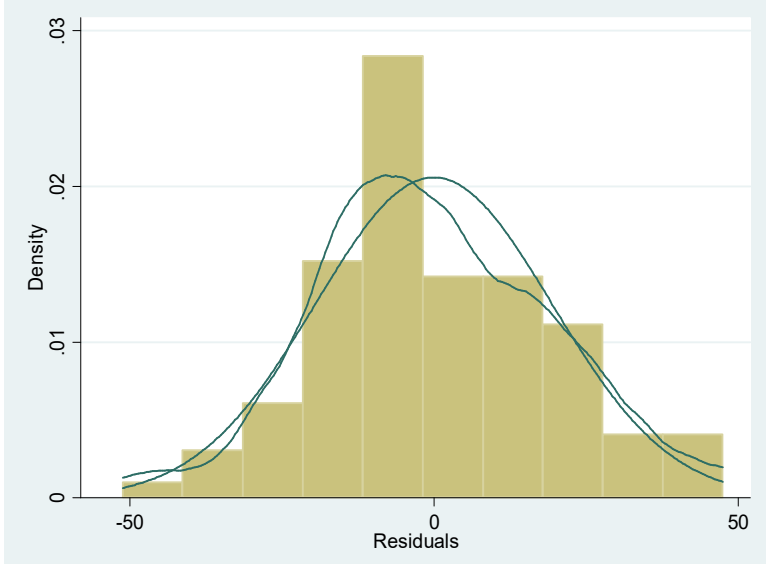

- histogram e, kdensity normal

(bi $n=10$, start $=-51.126411$, width=9.8667923)

- mvtest normality e

Test for multivariate normality

Doornik-Hansen

chi2 2 (2) $=0.659 \quad$ Prob>chi2 $=0.7191$ 


\section{The OLS regression result}

- reg Inccp imsd fams fe edu fs age sex cr $i$

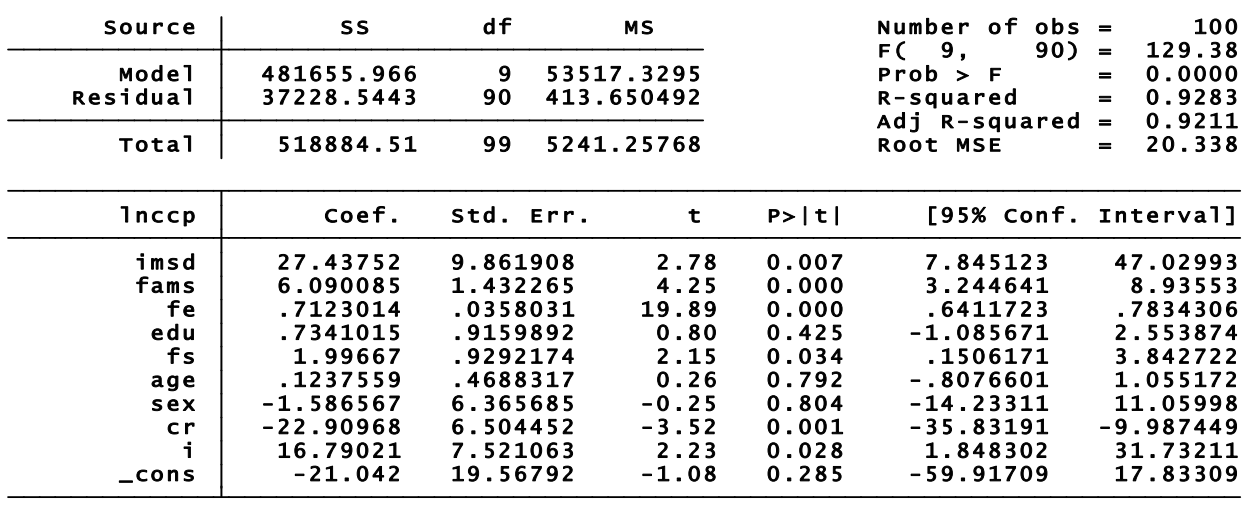

